\title{
Overview of lasers in dermatology
}

\author{
K. Kelly, J. Stuart Nelson
}

K. M. Kelly, J. Stuart Nelson M.D., "Overview of lasers in dermatology," Proc. SPIE 10297, Matching the Energy Source to the Clinical Need: A Critical Review, 1029702 (24 January 2000); doi: 10.1117/12.375211

SPIE. Event: Digital Optical Computing, 1990, Los Angeles, United States 


\title{
Overview of lasers in dermatology
}

\author{
K.M. Kelly and J.S. Nelson \\ Departments of Dermatology and Surgery \\ Beckman Laser Institute and Medical Clinic \\ University of California, Irvine
}

\begin{abstract}
Research over the last 40 years has provided information on laser-tissue interactions and led to the development of many lasers used for a variety of dermatologic procedures. In this review, we discuss the current state of laser use in dermatology including the treatment of vascular lesions, tattoo removal, treatment of pigmented lesions, hair removal and laser skin resurfacing. In addition, we note several issues which need to be addressed in order to achieve an improved therapeutic outcome without adverse effects.
\end{abstract}

Keywords: Laser, port wine stain, tattoo, nevi, hair removal, laser skin resurfacing

\section{INTRODUCTION}

An improved understanding of the optical characteristics of human skin has allowed researchers to concentrate on basic physical and photobiologic principles of lasertissue interaction. Lasers utilized in the 1960s, 1970s, 1980s, and early 1990s offered few possibilities for modification. However, modern technology allows us to manipulate the physical characteristics of lasers and design them for specific therapeutic purposes.

\subsection{Selective Photothermolysis and Spatially Selective Photocoagulation}

The laser has many inherent physical properties that can be manipulated to effect a specific biologic outcome. Selective photothermolysis was described by R. Rox Anderson in 1983 as a means of achieving targeted chromophore destruction and remains the guiding principle for laser dermatology today ${ }^{1}$. Wavelength and pulse duration of light exposure are central to this concept.

In order to achieve selective damage of a chromophore within human skin, the laser wavelength must approximate an absorption peak of the targeted chromophore in relation to other optically absorbing molecules. Choice of wavelength also determines the depth to which light penetrates with sufficient energy to effect tissue change. In the case of cutaneous blood vessels, the targeted chromophore is oxyhemoglobin $\left(\mathrm{HbO}_{2}\right)$ which has the Soret absorption band at $418 \mathrm{~nm}$ and additional absorption bands at 542 and $577 \mathrm{~nm}$. While the Soret band has the highest absorption

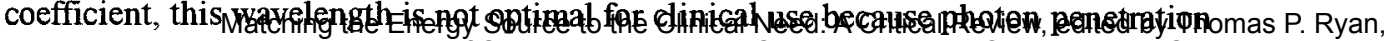
Proc. of SPIE Vol. 10297 (Vol. CR75), 1029702 - @ (2000) 2017 SPIE

CCC code: $0277-786 X / 17 / \$ 18 \cdot$ doi: $10.1117 / 12.375211$

3

Proc. of SPIE Vol. 10297 1029702-1 
is insufficient to destroy dermal vessels deeper than $0.1 \mathrm{~mm}$ from the surface. Further, light absorption by melanin, which is greatest in the ultraviolet range and decreases rapidly through the visible and near-infrared wavelengths, is higher at the Soret band as compared to the other $\mathrm{HbO}_{2}$ absorption peaks, resulting in nonspecific thermal injury of the epidermis. By taking advantage of the $\mathrm{HbO}_{2}$ absorption band at $577 \mathrm{~nm}$, tissue penetration is increased and melanin absorption reduced resulting in less epidermal heating and transmission of more incident light energy to the target blood vessels.

Pulse duration is another important laser parameter relevant to the goal of achieving precise control of thermal energy. One way to maximize the spatial confinement of heat is to use a laser with a pulse duration on the order of the thermal relaxation time $\left(T_{r}\right)$ of the targeted chromophore. $T_{r}$ is the duration required for the heat generated by absorbed light energy within the target chromophore to dissipate to $50 \%$ of its value immediately after laser exposure. This value is directly proportional to the square of the diameter of the target and inversely proportional to the thermal diffusivity of the tissue. Longer pulse durations result in heat diffusion away from the targeted structure leading to generalized heating and less spatial selectivity regardless of careful wavelength selection and may result in nonspecific thermal damage. However, if the laser pulse is suitably brief, energy is invested in the target chromophore before much heat is lost out of the exposure field by thermal diffusion resulting in a maximum transient temperature differential between the target and adjacent structures. Shorter pulse durations confine laser energy to small targets with more spatial selectivity. The transition from specific to nonspecific thermal damage occurs as the laser exposure equals and then exceeds $T_{r}$. Lasers emitting at a selectively absorbed wavelength with a pulse duration less than $T_{\mathrm{r}}$ can achieve highly selective target damage.

Selective photothermolysis significantly improved patient outcome; however, therapeutic challenges remained including incomplete lesion removal despite multiple treatments and a low, but significant incidence of adverse effects. In many cases, these problems arose because of nonspecific epidermal absorption of laser energy. Epidermal melanin represents an "optical barrier" through which the light must pass to reach the targeted dermal chromophore. Absorption of laser energy by epidermal melanin reduces the light dosage reaching the target, thereby decreasing the amount of heat produced in the target leading to sub-optimal removal of the lesion. Moreover, melanin absorption causes localized heating of the epidermis, which may, if not controlled, produce permanent complications such as scarring or dyspigmentation. Unfortunately, for many lesions the threshold for epidermal damage following laser therapy is lower than that for target chromophore destruction.

In an attempt to address the aforementioned problems, various cooling modalities including application of ice packs, chilled running water, and chilled substrates such as sapphire plates have been utilized to protect the epidermis during pulsed laser exposure ${ }^{2-4}$. However, none of the above has proven entirely satisfactory nor, most importantly, led to improved therapeutic outcome. All previously tried methods have failed due to the thermal response of human skin to sustained cooling when a nearsteady-state temperature distribution is established. Therefore, in addition to cooling 
the epidermis, sustained cooling also reduces the temperature of the targeted dermal chromophore. Any increase in the threshold fluence for epidermal damage achieved by a reduction in the temperature is almost entirely offset by the additional energy required to heat the target chromophores to a temperature sufficient for permanent lesion removal.

Spatially selective photocoagulation is the process of providing epidermal protection while still achieving thermal injury in the dermis. In 1994, Nelson et al. described a novel, efficient and effective method of achieving spatially selective photocoagulation, "dynamic" or cryogen spray cooling (CSC) ${ }^{5,6}$. A millisecond cryogen spurt is applied to the skin surface immediately before laser exposure allowing localized cooling of the epidermis without affecting the deeper targeted structures, leaving them susceptible to laser induced thermal injury. Spatially selective photocoagulation has been implemented most successfully for the treatment of port wine stain (PWS) birthmarks and other hypervascular skin lesions but has also been utilized to improve outcomes and decrease the incidence of adverse effects associated with other laser procedures including hair removal and laser skin resurfacing.

In this review, we discuss the current state of laser use in dermatology and note issues which remain to be addressed by future scientific innovations.

\section{TREATMENT OF VASCULAR LESIONS}

A wide variety of hypervascular skin lesions are amenable to laser therapy (Table 1). PWS are congenital vascular malformations which may be disfiguring as they are most often found on the face and neck. There is extensive literature on PWS laser therapy and in many cases similar treatment parameters can be applied to other vascular lesions on comparable anatomic locations. Lower extremity lesions such as leg veins require special consideration and will be discussed at the end of this section.

Table 1. Hypervascular lesions amenable to laser treatment

\begin{tabular}{|ll|}
\hline Port Wine Stains & Angiokeratomas \\
Capillary Hemangiomas & Spider Angiomas \\
Cherry Angiomas & Facial Telangiectasias \\
Venous Lakes & Telangiectatic Leg Veins \\
Poikiloderma of Civatte & \\
\hline
\end{tabular}

As previously discussed, the target chromophore for vascular lesions is $\mathrm{HbO}_{2}$ which has absorption peaks at 418,542 , and $577 \mathrm{~nm}^{7}$. The radiant energy of the laser is preferentially absorbed by $\mathrm{HbO}_{2}$ within the vascular lesion and converted to heat which results in thermal damage and vessel thrombosis. The argon laser was the first device utilized for the treatment of vascular lesions. However, this laser's blue-green light $(488,514 \mathrm{~nm})$ did not match any of the $\mathrm{HbO}_{2}$ absorption peaks and melanin absorption was significant at these relatively short wavelengths. Furthermore, the shortest achievable pulse duration was 0.01 second, far longer than the 1-10 milliseconds considered optimal based on the average diameter $(30-150 \mu \mathrm{m})$ of 
targeted blood vessels ${ }^{8,9}$. As a result, scarring was common occurring in up to $40 \%$ of infants and young children receiving laser treatment for PWS birthmarks ${ }^{10,11}$.

The flashlamp-pumped pulsed dye laser (FLPDL) was introduced in the early 1980s. This laser uses an organic dye as the lasing medium and can achieve high peak power, 0.45 millisecond, single pulses ideal for targeting specific chromophores. The 585 $\mathrm{nm}$ wavelength, although not one of the $\mathrm{HbO}_{2}$ absorption peaks, was determined to be optimal as it allows a greater depth of light penetration into human skin $(1.20 \mathrm{~mm}$ at $585 \mathrm{~nm}$ versus $0.50 \mathrm{~mm}$ at $577 \mathrm{~nm}$ ) while maintaining nearly the same degree of vascular specificity ${ }^{12}$. The FLPDL has become the treatment of choice for PWS and can achieve $50 \%$ fading in $75 \%$ of patients ${ }^{13}$.

Complete PWS fading after a single treatment using the FLPDL is rare. Most patients require multiple treatments of the same area to obtain optimal fading. The number of treatments required varies with anatomic location. Lesions overlying bony prominences, such as the nose, forehead and temple, generally respond faster than those on the lips and cheek. PWS on the trunk and extremities require more (10-20) treatments. Patients less than 7 years of age require fewer treatments to achieve optimal response than older patients. Flat, immature PWS achieve the best treatment response while nodular hypertrophic PWS respond the least. Treatments are repeated at 8-12 week intervals.

The safety of this therapy has been demonstrated in multiple studies ${ }^{14-17}$ as well as our own extensive experience ${ }^{18}$. Purpura, a bruised-like skin appearance, lasts 7-14 days post treatment and is the major morbidity following FLPDL irradiation. Hyperpigmentation occurs in up to $35 \%$ of patients but is temporary ${ }^{14-16}$. Scarring is uncommon, occurring in fewer than $5 \%$ of patients and is often treatable with topical or intralesional steroids ${ }^{15,17}$.

The FLPDL offers significant advantages over lasers previously utilized for vascular lesion removal; however, as noted above, incomplete lesion removal despite multiple treatments remains a clinically significant problem. Spatially selective photocoagulation is one method of improving therapeutic outcome while minimizing adverse effects. Candela Corporation's (Wayland, MA) ScleroPLUS $\circledast$ offers a pulse duration of $1.5 \mathrm{~ms}$ and wavelengths from $585-600 \mathrm{~nm}$ in combination with cryogen spray cooling (CSC). The longer pulse duration allows treatment of larger blood vessels and, because the vessels are heated more slowly, results in less purpura. The longer wavelengths allow laser light to penetrate further into individual vessels and permit injury of vessels deeper in the vascular plexus. However, at wavelengths longer than $585 \mathrm{~nm}$, light absorption by $\mathrm{HbO}_{2}$ rapidly decreases and higher fluences are required. CSC in combination with the FLPDL allows the use of higher incident laser light dosages which expedite PWS clearing ${ }^{19}$. In addition, treatment pain is decreased especially in patients with darker skin types ${ }^{20-22}$. Excellent PWS clearance without adverse effects has been reported for the treatment of PWS, hemangiomas, telangiectasia and other vascular lesions.

Coherent Inc. (Palo Alto, CA) offers a $532 \mathrm{~nm}$ potassium titanyl phosphate (KTP) laser containing a hand-piece with an attachable chilled sapphire plate that is cooled 
by circulating water. The chilled plate must be kept in close contact with the skin surface during laser irradiation. Pulse widths of $2-50 \mathrm{~ms}$ are available resulting in little or no post-treatment purpura as the vessel is heated slowly. Because of the absence of purpura, many patients prefer this option over pulsed dye laser treatment. Some success has been reported with the use of the KTP laser for the treatment of PWS ${ }^{23}$ and it may be an option for those lesions resistant to pulsed dye laser treatment. This laser has been used for treatment of facial telangiectasias with good results and minimal side effects ${ }^{24,25}$.

An alternative method for treating vascular lesions, an intense pulsed light source, (IPLS) was developed by Sharplan-ESC Medical Systems Ltd. (Yokneam, Israel). A high energy flashlamp emits non-coherent light $(515-1200 \mathrm{~nm})$ utilizing cut-off filters $(515,550,570$ or $590 \mathrm{~nm})$ to eliminate shorter wavelengths. It is suggested that the non-coherent light will allow thermocoagulation of a wide range of vessel sizes and depths ${ }^{26}$. Some good results have been reported utilizing this system for the treatment of facial PWS and telangiectasias ${ }^{24,27}$ but further research is required for technique optimization.

A wide variety of other hypervascular lesions including hemangiomas, cherry angiomas, spider angiomas, venous lakes, poikiloderma of Civatte, angiokeratomas, and facial telangiectasias have benefited from laser therapy which is now considered the treatment modality of choice.

Laser treatment of telangiectatic or spider leg veins is a topic which has generated considerable interest during the last several years. These vessels pose unique treatment challenges because of increased hydrostatic pressure and wide variability in target vessel size. There are currently many laser systems available for the treatment of leg veins (Table 2) each with unique options including cooling methods.

Table 2: Lasers available for the treatment of leg telangiectasia

\begin{tabular}{|c|c|c|}
\hline Laser/Manufacturer & Wavelengths & Special Features \\
\hline $\begin{array}{l}\text { Versa Pulse }{ }^{\circledR} \\
\text { Coherent, Inc. }\end{array}$ & $532 \mathrm{~nm}$ & Chilled tip \\
\hline $\begin{array}{l}\text { VeinLase }{ }^{\circledR} \\
\text { HGM }\end{array}$ & $532,1064 \mathrm{~nm}$ & \\
\hline $\begin{array}{l}\text { Photogenica VLS® - } \\
\text { Pulsed Dye Laser } \\
\text { Cynosure }\end{array}$ & $585-600 \mathrm{~nm}$ & \\
\hline $\begin{array}{l}\text { ScleroPLUS } \circledast \\
\text { Candela Corporation }\end{array}$ & $585-600 \mathrm{~nm}$ & $\begin{array}{c}1.5 \mathrm{~ms} \text { pulse duration } \\
\text { Dynamic Cooling } \\
\text { Device }\end{array}$ \\
\hline $\begin{array}{l}\text { LPIR-Alexandrite laser( } \\
\text { Cynosure }\end{array}$ & $755 \mathrm{~nm}$ & \\
\hline $\begin{array}{l}\text { Vasculight }{ }^{\circledR} \\
\text { ESC/Sharplan }\end{array}$ & $1064 \mathrm{~nm}$ & \\
\hline $\begin{array}{l}\text { Photoderm VL/PL@ } \\
\text { ESC/Sharplan }\end{array}$ & $515-1200 \mathrm{~nm}$ & $8 \times 35 \mathrm{~mm}$ handpiece \\
\hline
\end{tabular}


An extensive discussion of the advantages and disadvantages of each of these lasers is beyond the scope of this review. However, a clinically significant incidence of side effects especially hyper- and hypo-pigmentation, is generally reported and treatment results are highly variable ${ }^{23,28}$. Most experts agree that sclerotherapy remains the treatment of choice for lower leg telangiectasias but laser treatment may be useful in patients with small spider veins $(<0.5 \mathrm{~mm}$ diameter), those refusing sclerotherapy secondary to needle phobia, and those with telangiectatic matting.

\section{TATTOO REMOVAL}

Previous methods of tattoo removal included excision with primary closure or skin grafting, mechanical dermabrasion, salabrasion, cryosurgery, or application of caustic chemicals such as phenol, all of which resulted in significant scarring. Argon and carbon dioxide lasers were the first lasers evaluated for tattoo removal ${ }^{29-31}$. However, those lasers eliminated tattoo pigment by removal of successive layers of skin rather than color-selective light absorption. Non-specific thermal damage occurred which resulted in subsequent scar formation.

Organometallic dyes, India ink, amorphous carbon and graphite typically found in amateur and professional tattoos have a broad absorption in the visible portion of the light spectrum. At visible wavelengths longer than $600 \mathrm{~nm}, \mathrm{HbO}_{2}$ and melanin light absorption is minimized and tattoo dyes can be targeted selectively ${ }^{32}$. The pigment granules characteristically found in tattoos have diameters of $0.5-100 \mu \mathrm{m}$ which corresponds to thermal relaxation times of $20 \mathrm{~ns}$ to $3 \mathrm{~ms}^{1}$.

With the development of Q-switched lasers, each with a unique wavelength able to target different pigments (Table 3 ), tattoo removal without scarring could be achieved for the first time. Q-switching is a mechanism used to control light output by concentrating energy into a single, intense pulse of nanosecond duration. A Pockel's cell or fast electromagnetic switch causes excitation of the active medium to build up in the laser cavity. Lasing is prevented by a shutter which is then opened resulting in a burst of energy. The Q-switched ruby laser utilizes high intensity flashlamps to excite a ruby crystal (aluminum trioxide doped with chromium ions) and emits red light at a wavelength of $694 \mathrm{~nm}$. The Q-switched Alexandrite laser is a solid-state laser containing a chrysoberyl crystal of aluminum tetraoxide $\left(\mathrm{BeO}: \mathrm{Al}_{2} \mathrm{O}_{3}\right)$ doped with $\mathrm{Cr}$ ions and also emits red light but with a wavelength of $755 \mathrm{~nm}$.

Table 3. Q-switched lasers for the treatment of tattoos

\begin{tabular}{|l|c|c|}
\hline Laser & Wavelengths (nm) & Tattoo Color \\
\hline QS Ruby & 694 & Blue, Black, Green \\
\hline QS Alexandrite & 755 & Multi-colored \\
\hline QS Nd:YAG & 1064 & Multi-colored \\
\hline QS frequency doubled Nd:YAG & 532 & Red \\
\hline
\end{tabular}


The Q-switched Nd:YAG laser contains a crystal of yttrium aluminum-garnet (YAG) doped with neodymium (Nd) ions which is excited by xenon arc lamps to emit a near infra-red wavelength of $1064 \mathrm{~nm}$. Tattoo pigment absorption is decreased at this longer wavelength but the light is sufficiently absorbed to achieve selective photothermolysis. Benefits of this laser include deeper light penetration $(4-6 \mathrm{~mm})$ into human skin and decreased melanin light absorption and thus, a decreased risk of dyspigmentation. The frequency doubled Q-switched Nd:YAG laser is created by inserting a KTP crystal in the light beam's path resulting in an emitted wavelength of $532 \mathrm{~nm}$ which provides improved removal of red dye.

The exact mechanism of laser tattoo removal is unknown but several theories have been postulated ${ }^{33}$. First, during Q-switched laser treatment, light energy is absorbed by the pigment and converted to heat, causing a chemical alteration in the pigment granule structure sufficient to alter the optical properties of the tattoo, making it less apparent. Second, the altered tattoo pigment particles are eliminated by rephagocytosis. Third, external elimination occurs as post-treatment crust is sloughed.

Complete tattoo removal after one treatment is rare. Multiple treatment sessions are required and complete elimination can not be guaranteed due to pigment depth and chemical composition variability. Amateur tattoos generally have a lower concentration of pigment and therefore require fewer treatments than those professionally done. Further, the organometallic dyes used for professional tattoos may be thermally and mechanically more stable than the India ink, graphite, amorphous carbon, and cigarette ash found in amateur tattoos. Dark colors, especially black and blue, generally have higher absorption and respond better to laser treatment than light colors. Orange and yellow respond least well. Lasers are also useful for removal of traumatic and cosmetic tattoos.

While lasers have dramatically reduced the incidence of scarring associated with tattoo removal, other adverse effects do occur. Post-treatment hyper- and hypopigmentation are the most common. Strict sun avoidance pre- and post-treatment is important to minimize this risk. Red, white, and flesh-colored tattoos generally used for eyebrow, eye or lip liner have changed to black, brown, blue or green after laser treatment. The mechanism of this change may involve the reduction of ferric oxide $\left(\mathrm{Fe}_{2} \mathrm{O}_{3}\right)$ pigment to ferrous oxide $(\mathrm{FeO})^{34}$. Some reported cases responded to further laser sessions but others required surgical excision ${ }^{34,35}$. Since the occurrence of this adverse effect can not be accurately predicted and may not be immediately apparent, test sites are advisable. Cutaneous and even occasionally systemic allergic reactions to altered tattoo pigments especially cadmium, chromium, cobalt or mercury containing inks have also been reported ${ }^{36}$. Prophylaxis with prednisone and hydroxyzine may be required for subsequent treatments.

Future possibilities for improved tattoo removal include the use of lasers with picosecond pulse durations ${ }^{37,38}$. It has been proposed that while the nanosecond pulse duration of Q-switched lasers results in thermal damage confinement to the pigmented granule, thermoelastic expansion occurs resulting in mechanical stress. 
Lasers with picosecond pulse durations may confine both thermal and photomechanical damage and thus, achieve more effective pigment removal. In the future it may also be possible to define tissue reflectance characteristics of individual tattoos to help determine which laser will achieve maximum absorption and destruction of the targeted pigment color ${ }^{39}$. Finally, the development of inks more amenable to laser removal and the use of spatially selective photocoagulation for this indication have been proposed.

\section{TREATMENT OF PIGMENTED LESIONS}

Lasers have also been successfully utilized to treat a wide variety of pigmented lesions (Table 4). The target chromophore is melanin and lesion resolution is thought to be secondary to melanosome disruption as a result of thermal injury or shock wave induced thermal expansion ${ }^{40,41}$. Melanin has a broad absorption spectrum and thus, green, red and near-infrared lasers have been utilized for this indication.

Table 4. Pigmented lesions amenable to laser treatment

\begin{tabular}{|ll|}
\hline $\begin{array}{l}\text { Lentigines } \\
\text { Ephelides } \\
\text { Nevus of Ito }\end{array}$ & Nevus of Ota \\
& Nevi - Acquired and Congenital \\
(Controversial)
\end{tabular}

Green light lasers used for pigment lesion removal include the $510 \mathrm{~nm}$ FLPDL with a $300 \mathrm{~ns}$ pulse duration and the frequency-doubled Q-switched Nd:YAG laser with a 510 ns pulse duration. The relatively short green light wavelength does not penetrate the dermis deeply and thus, these lasers are effective only for the treatment of epidermal pigmented lesions such as lentigines ${ }^{42}$. In addition, green light is also highly absorbed by $\mathrm{HbO}_{2}$ and therefore, purpura is often noted after treatment.

Red light is well absorbed by melanin and penetrates up to $1 \mathrm{~mm}$ into human skin. In addition, red light is not absorbed by $\mathrm{HbO}_{2}$ so there is no post-treatment purpura. Therefore, Q-switched ruby and alexandrite lasers are generally considered the treatment of choice for dermal as well as epidermal melanoses.

Finally, the Q-switched Nd:YAG laser has been used for the treatment of pigmented lesions. Because of the decreased melanin absorption at this wavelength, this laser is most advantageous for treatment of patients with darker skin types who are at increased risk of adverse effects as a result of high non-specific epidermal melanin light absorption and subsequent injury. The ability of this laser to penetrate 4-6 mm into human skin makes it effective for treatment of dermal melanoses such as nevi of Ito and Ota.

Some pigmented dermatoses are more amenable to laser therapy than others. Nevus spilus, café-au-lait macules, and Becker's nevi often recur even after clinical resolution. Recurrences may result because lasers damage the melanosomes and not the pigment producing melanocytes ${ }^{42}$. Treatment of melasma generally yields poor results ${ }^{43}$ possibly because of a multi-factorial etiology involving genetics, hormonal influence and sun induction. Post-inflammatory ${ }^{43}$ and infra-orbital 
hyperpigmentation ${ }^{44}$ have also been treated utilizing the Q-switched ruby laser and in some cases improvement has been noted; however, results were variable. For any pigmented lesion, it may be difficult to predict which laser will be most effective and test spots are often useful.

The treatment of nevi is an issue currently generating significant interest. Controversy arises because the effect of lasers on melanocytes, cells with malignant potential, is undefined. Although lasers have been used for years to treat pigmented lesions such as Nevus of Ota, there have been no reports of malignant transformation. This is encouraging; however, the potential risk of litigation in the United States has made clinicians reluctant to treat nevi. Recently, Rosenbach et al. utilized the Qswitched alexandrite and Nd:YAG lasers for the treatment of flat, clinically benign, acquired nevi ${ }^{45}$. Significant clinical lightening was achieved after three treatments accompanied by a histologic decrease in the number of epidermal and dermal melanocytes. Since this report, some physicians are offering laser treatment of similar lesions.

The treatment of congenital nevi has been particularly thought provoking because these lesions are believed to have an increased malignant potential. The Q-switched ruby and Q-switched Nd:YAG lasers have been used to treat small and medium sized congenital nevi with some success ${ }^{46,47}$. Utilizing the Q-switched ruby laser, Waldorf et al. ${ }^{48}$ achieved an average improvement of $76 \%$ clearance after eight treatment sessions. Five patients achieved $90 \%$ clearance after additional treatment sessions. However, at least partial repigmentation was noted in nearly all lesions after therapy discontinuation. Better results have been reported from Japan using the long-pulsed (300-1000 $\mu \mathrm{s})$ ruby laser ${ }^{49}$. Significant reduction was achieved in the nevi of three patients after four treatments with minimal or no recurrence 18-39 months posttherapy.

We reported the complete clinical resolution of a medium sized congenital nevus using the Q-switched ruby laser ${ }^{50}$. The lesion was cosmetically disfiguring and its size precluded surgical excision. No recurrence has been noted in six years since the final treatment. The lack of lesion recurrence in this case was likely secondary to the relatively superficial nature of the dermal melanocytes.

At this time, lasers should be considered for the treatment of congenital nevi that are difficult or impossible to excise and located on highly visible areas where they are likely to cause significant cosmetic morbidity. However, the patient and/or family members must be carefully informed of the potential risks and the need for lifelong surveillance of the lesional area.

\section{LASER HAIR REMOVAL}

In 1995, the FDA approved the first laser system designed for long-term hair removal based on the principles of selective photothermolysis ${ }^{51}$. Since that time, a multitude of lasers and light sources have been developed for this indication (Table 5). 
Table 5. Lasers available for hair removal

\begin{tabular}{|c|c|c|c|}
\hline $\begin{array}{l}\text { Product Name/ } \\
\text { Manufacturer }\end{array}$ & Laser Type & $\begin{array}{c}\text { Wavelength } \\
(\mathrm{nm})\end{array}$ & Special Features \\
\hline $\begin{array}{c}\text { RubyStar }{ }^{\circledR} \\
\text { Aesculap-Meditec }\end{array}$ & $\begin{array}{l}\text { Long-Pulsed } \\
\text { Ruby }\end{array}$ & 694 & Cooling System \\
\hline $\begin{array}{c}\text { Epilaser }{ }^{\circledR} \\
\text { Coherent }\end{array}$ & $\begin{array}{l}\text { Long-Pulsed } \\
\text { Ruby }\end{array}$ & 694 & $\begin{array}{c}\text { Sapphire-tipped } \\
\text { cooling hand-piece }\end{array}$ \\
\hline $\begin{array}{l}\text { EpiTouch Ruby® } \\
\text { ESC/Sharplan }\end{array}$ & $\begin{array}{l}\text { Long-Pulsed } \\
\text { Ruby }\end{array}$ & 694 & Cooling gel \\
\hline $\begin{array}{l}\text { GentleLase } \AA \\
\text { Candela }\end{array}$ & $\begin{array}{l}\text { Long-Pulsed } \\
\text { Alexandrite }\end{array}$ & 755 & Dynamic Cooling Device \\
\hline $\begin{array}{l}\text { Apogee LPIR } \mathbb{8} \\
\text { Cynosure }\end{array}$ & $\begin{array}{l}\text { Long-Pulsed } \\
\text { Alexandrite }\end{array}$ & 755 & Cooling gel \\
\hline $\begin{array}{c}\text { EpiTouch Alex® } \\
\text { ESC/Sharplan }\end{array}$ & $\begin{array}{l}\text { Long-Pulsed } \\
\text { Alexandrite }\end{array}$ & 755 & Cooling gel \\
\hline $\begin{array}{l}\text { LightSheer }{ }^{\circledR} \\
\text { Coherent }\end{array}$ & $\begin{array}{l}\text { Long-Pulsed } \\
\text { Diode }\end{array}$ & 800 & ChillTip hand-piece \\
\hline $\begin{array}{l}\text { Epistar }{ }^{\circledR} \\
\text { Nidek }\end{array}$ & $\begin{array}{l}\text { Long-Pulsed } \\
\text { Diode }\end{array}$ & 800 & \\
\hline $\begin{array}{l}\text { Medlite IV® } \\
\text { Continuum } \\
\text { Biomedical }\end{array}$ & $\begin{array}{l}\text { Q-switched } \\
\text { Nd:YAG }\end{array}$ & $1064 / 532$ & \\
\hline $\begin{array}{l}\text { SoftLight }{ }^{\circledR} \\
\text { Thermolase }\end{array}$ & $\begin{array}{l}\text { Q-switched } \\
\text { Nd:YAG }\end{array}$ & 1064 & $\begin{array}{c}\text { Utilizes carbon } \\
\text { suspension; scanner }\end{array}$ \\
\hline $\begin{array}{c}\text { Orion }{ }^{\circledR} \\
\text { Laserscope }\end{array}$ & $\begin{array}{l}\text { Long-Pulsed } \\
\text { Nd:YAG } \\
\end{array}$ & 1064 & Contact cooling \\
\hline $\begin{array}{l}\text { Vasculight }{ }^{\circledR} \\
\text { ESC/Sharplan }\end{array}$ & $\begin{array}{l}\text { Long-Pulsed } \\
\text { Nd:YAG }\end{array}$ & 1064 & Contact cooling \\
\hline $\begin{array}{c}\text { VeinLase }{ }^{8} \\
\text { HGM }\end{array}$ & $\begin{array}{l}\text { Long-Pulsed } \\
\text { Nd:YAG } \\
\end{array}$ & 1064 & \\
\hline $\begin{array}{c}\text { Epilight }{ }^{\circledR} \\
\text { ESC/Sharplan }\end{array}$ & Pulsed Light & $550-1200$ & $\begin{array}{l}8 \times 35 \mathrm{~mm} \text { or } 10 \times 45 \mathrm{~mm} \\
\text { hand-piece; } \\
\text { Cooling gel }\end{array}$ \\
\hline
\end{tabular}

The target chromophore for laser hair removal is melanin and thus, the ideal candidate is a patient with light skin and dark hair. The follicular structure responsible for regeneration has not been identified and current systems target the entire follicle ${ }^{52}$. This requires the use of long pulse widths, on the order of milliseconds, and high fluences capable of heating a large volume of tissue ${ }^{52}$. Large spot sizes are also beneficial as they penetrate deeper into the dermis and result in more uniform heating. 
Despite the considerable interest in this area, none of the currently available systems (an achieve consistent, complete, and permanent hair removal. For approval, the PDA requires demonstration of only a $30 \%$ decrease in hair growth 3 months after a single treatment ${ }^{52}$. Obviously, this definition is not equivalent to permanent hair enorotal as the duration of telogen may exceed three months. In an effort to set a mare meaningful standard for successful treatment, Dierickx et al. defined "permanent hair removal" as a significant reduction in the number of terminal hairs fraperiod longer than the follicle growth cycle at the relevant body site ${ }^{53}$. Thus far, sme patients have experienced "permanent hair removal" by this definition using a bia-pulsed ruby laser ${ }^{53}$, a diode laser ${ }^{54}$, or the intense pulsed light source ${ }^{55}$. The magity of patients undergoing laser hair removal report only a significant delay (enererally 3-9 months) in hair re-growth ${ }^{56}$.

Pemanent hair removal is difficult to achieve for a variety of reasons. Hair follicles atc capable of regeneration, although as previously noted, the pleuripotential cell sure is unknown. Currently, the bulge and the dermal papilla are considered the mos likely candidates. Further, the size and melanin content of follicles vary with andomic location and growth cycle phase (anagen, catagen or telogen) making them more difficult to target. Finally, the removal of red, blonde, white or gray hair is iffall because the targeted chromophore, melanin, is altered in composition and quantity and as a result, light absorption is diminished ${ }^{57}$.

Lasss can generally achieve longer delays in hair re-growth than traditional methods sch as shaving, tweezing, waxing and chemical depilation ${ }^{58}$. In addition, lasers are gancrally faster and less painful than electrosurgical depilation and the incidence of aberse effects is low. In a recent study, Nanni and Alster ${ }^{59}$ reviewed the charts of 900 patients who underwent laser hair removal. Most if not all patients experienced tansient erythema and peri-follicular edema which generally resolved within 4 hours. Folliculitis and skin dyspigmentation were the next most common side effects but gagin, were temporary. Long term sequelae including scarring, did not occur in this sidly.

Pdients with dark skin types who have a higher concentration of epidermal melanin, ale at greatest risk for epidermal damage and skin dyspigmentation during hair enoral. The use of longer wavelengths and pulse widths is useful in these patients tot the best results have been achieved with laser systems which have implemented qaailly selective photocoagulation utilizing cooling gel, sapphire tip contact cooling ac SC.

Funther research is required in this area of laser dermatology to make hair removal more complete, longer lasting and consistent in patients with all skin and hair types. Hair temoval utilizing aminolevulinic acid and photodynamic therapy has been Ieprited ${ }^{60}$ and may offer an improved option in the future.

\section{LASER SKIN RESURFACING (LSR)}

For enturies, patients have sought treatment for rhytides and photodamage. Previous thenpeutic options included dermabrasion, chemical peels, and topical medications 
including tretinoin and glycolic acids. During the last decade, infrared lasers introduced for this indication, have generated a great deal of attention from the media, patients and physicians. These lasers are capable of precise and complete ablation of human skin and offer several advantages over other treatment modalities.

The carbon dioxide $\left(\mathrm{CO}_{2}\right)$ laser has a wavelength of $10,600 \mathrm{~nm}$ which is highly absorbed by tissue water. Ninety-eight percent of the incident energy is absorbed within the most superficial $0.01 \mathrm{~mm}$. The unique characteristics of the $\mathrm{CO}_{2}$ laser make it a versatile surgical tool which can be used either for surgical incisions or volume ablation by vaporization of skin as utilized for the treatment of rhytides known as laser skin resurfacing (LSR). Rapid, localized heating results in tissue ablation with boiling and vaporization of intracellular water into a plume containing steam and charred tissue. While the removal of photodamaged skin is the most common indication for this procedure, LSR can also be utilized for treatment of a variety of skin lesions including acne scars (Table 6).

Table 6. Ablative laser applications

\begin{tabular}{|l|l|}
\hline Rhytid Ablation - Laser Resurfacing & Adenoma Sebaceum \\
Acne Scars & Angiokeratomas \\
Epidermal Nevus & Angiolymphoid Hyperplasia \\
Bowen's Disease & Pearly Penile Papules \\
Actinic Keratoses & Venous Lakes \\
Actinic Cheilitis & Lichen Sclerosus et Atrophicus \\
Oral Florid Papillomatosis & Zoon's Balanitis \\
Seborrheic Keratoses & Hailey-Hailey Disease \\
Syringomas & Granuloma Faciale \\
Trichoepitheliomas & Neurofibromas \\
Trichilemmomas & Myxoid Cysts \\
Xanthelasma & Rhinophyma \\
Apocrine Hidrocystoma & Mycosis Fungoides \\
Verruca & \\
\hline
\end{tabular}

The first devices used for LSR were $\mathrm{CO}_{2}$ lasers that delivered light in a continuous wave mode which resulted in non-specific thermal damage and scarring. Ablative lasers capable of high peak powers with short pulse durations were required to achieve more precise tissue removal. Two methods were utilized to obtain this goal. First, lasers were developed that achieve high peak powers in discrete millisecond pulses. This reduced pulse duration results in more superficial tissue vaporization which limits the zone of thermal injury. The most recent models have pulse durations less than $100 \mu$ s resulting in more rapid healing ${ }^{61}$ and less erythema ${ }^{62}$. The second method combined a continuous mode low power $\mathrm{CO}_{2}$ laser with a computerized scanner. Each individual skin site is exposed to the laser energy for a millisecond or less by rapidly scanning the beam over a geometric pattern. High powers can be obtained by focusing the laser beam onto a small spot size.

The computerized pattern generator ${ }^{\circledR}$ (CPG) developed by Coherent (Palo Alto, CA) is an automatic scanning device which is integrated into the laser to provide a precise, 
rapid, non-overlapping series of pulses in a pre-designated pattern. The CPG allows the clinician to vary the pattern, size and density of pulses and increases the speed and uniformity of $\mathrm{CO}_{2}$ resurfacing.

More recently, Erbium:Yttrium Aluminum Garnet (Er:YAG) lasers have been introduced. A pulsed flashlamp excites a YAG crystal doped with erbium to emit a wavelength of $2940 \mathrm{~nm}$ which is absorbed by water sixteen times more efficiently than the $\mathrm{CO}_{2}$ laser wavelength. The Q-switched mode can be utilized to achieve pulse durations with nanosecond intervals. These two factors combine to produce more superficial ablation.

Actinically damaged skin is characterized by epidermal atrophy and irregularity ${ }^{62}$. Keratinocytes vary in shape and size and are atypical. Melanocyte number and size are increased and melanin is unevenly distributed to the keratinocytes resulting in irregular skin pigmentation. In the dermis, glycosaminoglycans are increased replacing destroyed collagen. Elastic fibers are abundant, thickened and tortuous.

After $\mathrm{CO}_{2} \mathrm{LSR}$, the following histologic improvements are noted ${ }^{63}$. Epidermal atrophy and atypia are eliminated and replaced by normal epithelium with uniform keratinocytes. Melanocyte hypertrophy is eliminated and melanin is distributed evenly to the keratinocytes. In the dermis, glycosaminoglycans are decreased and replaced by new collagen and elastic fibers.

The mechanism of rhytid improvement post LSR has been debated and is likely multi-factorial ${ }^{64}$. Some skin irregularities are removed by direct tissue ablation ${ }^{63}$. Tissue shrinkage is another important factor and can be observed as the treatment is performed. This phenomenon is thought to be secondary to tissue dehydration and contraction of denatured collagen ${ }^{65}$. In addition, an increase in smooth muscle actin filaments has been reported post LSR ${ }^{66,67}$. During wound healing, contraction of these filaments may provide a scaffold for collagen deposition and remodeling which occur as laser induced thermal damage is repaired ${ }^{64}$. Post-operative healing leaves a smooth skin surface with the above described histologic improvements.

The outcome of LSR is dependent on the total depth of dermal injury which includes the extent of ablation plus residual thermal damage. The $\mathrm{CO}_{2}$ laser heats the skin surface in a self-limited and controlled manner ${ }^{68}$. Thirty to seventy-five micrometers of tissue are removed per pass until a plateau is reached at a depth of $200-250 \mu \mathrm{m}{ }^{69}$. The depth of residual thermal damage is dependent on the fluence and laser pulse duration and can reach a maximum of $150-180 \mu \mathrm{m}^{65,70}$. Blood vessels are coagulated during treatment and therefore, bleeding is generally minimal. At standard fluences, Er:YAG lasers are almost purely ablative, removing 10-40 $\mu \mathrm{m}$ of tissue per pass while the zone of thermal necrosis is limited to $50 \mu \mathrm{m}$ or less ${ }^{71}$. As a result, bleeding is common and may impair the procedure. Tissue ablation depth does not plateau and correlates linearly with the number of laser passes ${ }^{72}$.

Clinically, patients can expect $50 \%$ or greater improvement in wrinkle severity after $\mathrm{CO}_{2} \mathrm{LSR}^{73}$. Rhytides in areas of strong muscle activity such as the glabellar area respond least well whereas peri-orbital and -oral responses are better and similar ${ }^{74}$. 
Khatri et al. ${ }^{75}$ demonstrated that Er:YAG lasers at $5-8 \mathrm{~J} / \mathrm{cm}^{2}$ produce more superficial ablation, result in faster healing and are less effective at rhytid improvement when compared to $\mathrm{CO}_{2}$ laser treatment of an equivalent number of passes performed at a similar pulse fluence. If the number of Er:YAG laser passes is increased to 5 or more, ablation depth, speed of healing and rhytid improvement are equivalent to $\mathrm{CO}_{2}$ laser resurfacing.

A variety of adverse effects have been reported with LSR. The most common is skin dyspigmentation. The incidence of post-inflammatory hyperpigmentation is increased in patients with darker skin types. Studies have reported hyperpigmentation in up to $80 \%$ of skin type IV individuals with LSR of the peri-oral area ${ }^{76}$. This pigment change is noted 1-3 months after the procedure and generally resolves by postoperative month 3-4 with the use of bleaching agents and sun avoidance.

Delayed hypopigmentation may occur 3-10 months after resurfacing. The skin often appears normal after the resolution of erythema but before the onset of hypopigmentation. This adverse effect may occur in all skin types and the risk may be increased in those with more extensive photodamage ${ }^{77}$.

Other adverse effects include infectious and allergic complications such as impetigo, candidiasis, Kaposi's varicelliform eruption and allergic contact dermatitis. The incidence of these events has decreased with the use of improved pre- and postoperative care ${ }^{78}$. Milia and acneiform lesions occur three to six weeks after LSR in up to $83 \%$ of patients but are easily treated with tretinoin or extraction ${ }^{77}$.

Er:YAG LSR may be associated with a decreased incidence of adverse effects ${ }^{75}$. Thus, some physicians perform 1-2 passes of the $\mathrm{CO}_{2}$ laser followed by 1-2 passes of the Er:YAG ${ }^{79}$ in an effort to achieve maximum rhytid removal while decreasing the incidence of side effects. Cynosure, Inc. (Chelmsford, MA) and Sciton (Palo Alto, CA) have developed variable pulse duration Er:YAG lasers with a similar goal. It remains unclear whether these modifications are beneficial.

While ablative lasers can achieve good treatment results, removal of the epidermis results in an open wound which requires considerable post-operative wound care and puts the patient at risk for the complications described above. In an effort to improve rhytides while decreasing or eliminating the incidence of these adverse effects, attempts at nonablative skin resurfacing have been made. Laser Aesthetics (Auburn, CA) developed a $1320 \mathrm{~nm} \mathrm{Nd:YAG} \mathrm{laser} \mathrm{which} \mathrm{in} \mathrm{combination} \mathrm{with} \mathrm{CSC,} \mathrm{is} \mathrm{capable}$ of stimulating tissue fibroblasts ${ }^{80}$ without epidermal injury. In a multi-center study, 35 adults with peri-orbital rhytides were treated with 3 nonablative laser treatments performed sequentially at intervals of 2 weeks. Small but statistically significant improvements were noted in mild, moderate and severe rhytid groups twelve weeks after the final treatment. Only the severe rhytid group showed statistically significant improvement 24 weeks after the last treatment. Adverse effects were limited to transient hyperpigmentation (5.6\%) and a low incidence $(2.8 \%)$ of barely perceptible pin-point pitted scars. This study demonstrated that CSC is a safe and promising method for protecting the epidermis during nonablative laser treatment of facial rhytides and can be used to avoid much of the morbidity associated with other 
resurfacing modalities. Additional work should increase the efficacy of this and other nonablative resurfacing systens which may be utilized more commonly in the future.

\section{ISSUES TO BE ADDRESSED}

The role of the laser in clinical dermatology has significantly progressed during the last forty years and a wide variety of conditions and lesions can be successfully treated. However, as noted throughout this review, problems remain to be solved in order to achieve improved therapeutic outcomes without adverse effects.

First, for several clinical indications, the exact mechanism of the laser's effect is unclear. For tattoo and pigmented lesion removal, hair removal and LSR, mechanistic proposals have been made but not definitively proven. This incomplete understanding of laser-tissue interactions results in sub-optimal treatment. Patients seeking removal of tattoos or dermal melanoses often require ten or more treatments and even then, complete removal is often not achieved. Nevi, when treated, can be lightened or diminished in size but complete clinical removal is rare. The mode of action of laser hair removal is even less well defined as the follicular source of regeneration and thus, the optimal target, remains unknown. As a result, only hair reduction, not true elimination, is generally achieved, and even this is often temporary. The precise mechanism of rhytid improvement associated with traditional resurfacing methods is undefined and thus, has been difficult to replicate with nonablative methods.

Second, the effects of lasers on sub-cellular structures including DNA have not been elucidated. As a result, safety issues have been raised in regards to the laser treatment of nevi. While lasers can clearly remove or at least lighten congenital nevi, questions remain including whether laser treatment will decrease (by lessening the melanocytic load) or increase the risk of malignant transformation.

Third, the size and depth of the target chromophore and the epidermal melanin concentration are important variables affecting laser treatment. Current work is exploring methods to image and determine the depth and size of epidermal and dermal structures on an individual patient basis. This information combined with measurement of the patient's epidermal melanin concentration could be used to tailor laser wavelength, pulse duration and cooling parameters with the expectation of improving therapeutic outcome. These diagnostic techniques need to be improved to provide consistent accurate measurements and incorporated into widely available laser systems programmed to utilize the data.

Finally, spatially selective photocoagulation needs to be optimized. CSC is the most efficient method. Several fundamental questions regarding the thermodynamics of cryogen on the skin surface need to be addressed. Variables including cryogen selection, size and velocity of the cryogen droplets, delivery distance between the nozzle and skin surface and orientation of the cryogen spray relative to the skin surface, need to be further investigated and optimized in order to achieve improved treatment efficacy and decrease the incidence of side effects which occur as a result of epidermal injury. For conductive cooling, (i.e. gel or sapphire plates) issues 
regarding the timed application and removal of the devices need to be addressed and optimized.

\section{CONCLUSION}

The unique properties of lasers create an enormous potential for specific therapy of selective dermatoses. The most beneficial and appropriate use requires a thorough understanding of light and tissue interactions as well as laser properties. Future advances will require the efforts of physicians, engineers, chemists and physicists to match optimally the laser and treatment procedure to the targeted lesion.

\section{ACKNOWLEDGEMENTS}

This project was supported by research grant AR43419 from the Institute of Arthritis and Musculoskeletal and Skin Diseases at the National Institutes of Health (Dr. Nelson). Institutional support from the Department of Energy and the Beckman Laser Institute and Medical Clinic endowment at the University of California, Irvine is gratefully acknowledged.

\section{REFERENCES}

1. R.R. Anderson and J.A. Parrish, "Selective photothermolysis: precise microsurgery by selective absorption of pulsed radiation," Science 220 , pp. 524$529,1983$.

2. B.A. Gilchrest, S. Rosen, and J.M. Noe, "Chilling port wine stains improves the response to argon laser therapy," Plast. Reconst. Surg. 69, pp. 278-283, 1982.

3. U. Hohenleutner, T. Walther, M. Wenig, W. B'aumler and M. Landthaler, "Leg telangiectasia treatment with a $1.5 \mathrm{~ms}$ pulsed dye laser, ice cube cooling of the skin and 595 vs. $600 \mathrm{~nm}$ : preliminary results," Lasers Surg. Med. 23, pp. 72-78, 1998.

4. G.B. Altshuler, H.H. Zenzie, A.V. Erofeev, M.Z. Smirnov, R.R. Anderson and C. Dierickx, "Contact cooling of the skin," Phys. Med. Biol. 44, pp. 1003-23, 1999.

5. J.S. Nelson, T.E. Milner, B. Anvari, L.T. Norvang, N.H. Tran, B.S. Tanenbaum, and L.O. Svaasand, "Dynamic cooling of the epidermis during laser port wine stain therapy," Lasers Surg. Med. 6S, p. 48, 1994.

6. J.S. Nelson, T.E. Milner, B. Anvari, B.S. Tanenbaum, S. Kimel, L.O. Svaasand, and S.L. Jacques, " Dynamic epidermal cooling during pulsed laser treatment of port-wine stain. A new methodology with preliminary clinical evaluation," Arch. Dermatol. 131, pp. 695-700, 1995.

7. R.R. Anderson and J.A. Parrish, "The optics of human skin," J. Invest. Derm. 77, pp.13-19, 1981.

8. M.J.C. Van Gemert, A.J. Welch and A.P. Amin. "Is there an optimal laser treatment for port wine stains?," Lasers Surg. Med. 6, pp. 76-83, 1986.

9. C.C. Dierickx, J.M. Casparian, V. Venugopala, W.A. Farinelli and R.R. Anderson, "Thermal relaxation of port-wine stain vessels probed in vivo: the need for 1-10 millisecond laser pulse treatment," J. Invest. Derm. 105, pp. 709$714,1995$. 
10. J.A. Dixon, S. Huether and R. Rotering, "Hypertrophic scarring in argon laser treatment of port-wine stains," Plast. and Reconst. Surg. 73, pp. 771-779, 1984.

11. L. Silver "Argon laser photocoagulation of port wine stain hemangiomas," Lasers Surg. Med. 6, pp. 24-28, 1986.

12. O.T. Tan, O. Morrison and A.K. Kurban, " $585 \mathrm{~nm}$ for the treatment of port wine stains," Plast. Reconst. Surg. 86, pp. 1112-1117, 1990.

13. R. Ashinoff and R.G. Geronemus, "Flashlamp-pumped pulsed dye laser for portwine stains in infancy: earlier versus later treatment," J. Am. Acad. Derm. 24, pp. 467-472, 1991.

14. U. Wlotzke, U. Hohenleutner, T.A. Abd-El-Raheem, W. Baumler and M. Landthaler, "Side-effects and complications of flashlamp-pumped pulsed dye laser therapy of port-wine stains," Br. J. Dermatol. 134, pp. 475-480, 1996.

15. T.S. Alster and F. Wilson, "Treatment of port-wine stains with the flashlamppumped pulsed dye laser: extended clinical experience in children and adults," Ann. Plast. Surg. 32, pp. 478-484, 1994.

16. M.P. Goldman, R.E. Fitzpatrick and J. Ruiz-Esparza, "Treatment of port-wine stains (capillary malformation) with the flashlamp-pumped pulsed dye laser," $J$. Pediatrics 122, pp. 71-77, 1993.

17. D.C. Seukeran, P. Collins, and R.A. Sheehan-Dare, "Adverse reactions following pulsed tunable dye laser treatment of port wine stains in 701 patients," $\mathrm{Br} . J$. Dermatol. 136, pp. 725-729, 1997.

18. J.S. Nelson and J. Applebaum, "Clinical management of port-wine stain in infants and young children using the flashlamp-pulsed dye laser," Clin. Pediatr. 29, pp. 503-508, 1990.

19. J.C. Chang and J.S. Nelson, "Cryogen spray cooling and higher fluence pulsed dye laser treatment improve port wine stain clearance while minimizing epidermal damage," Dermatol. Surg. 25, pp. 767-772, 1999.

20. J.S. Nelson, T.E. Milner, B. Anvari, B.S. Tanenbaum, L.O. Svaasand and S. Kimel, "Dynamic epidermal cooling in conjunction with laser-induced photothermolysis of port wine stain blood vessels," Lasers Surg. Med. 19, pp. 224-229, 1996.

21. H.A. Waldorf, T.S. Alster, K. McMillan, A.N. Kauvar, R.G. Geronemus and J.S. Nelson, "Effect of dynamic cooling of 585-nm pulsed dye laser treatment of portwine stain birthmarks," Dermatol. Surg. 23, pp. 657-662, 1997.

22. E.J. Fiskerstrand, K. Ruggem, L.T. Norvan, and L.O. Svaasand, "Clinical effects of dynamic cooling during pulsed laser treatment of port wine stains," Skinlaser Today 7, pp. 25-37, 1998

23. R.M. Adrian, P. Graf, C. Grief and G. Burg, “ Treatment of vascular lesions using the VersaPulse ${ }^{\circledR}$ variable pulse width frequency doubled neodymium:YAG laser," Dermatol. 197, pp. 158-161, 1998.

24. T.B. West and T.S. Alster, "Comparison of the long-pulse dye (590-595nm) and KTP $(532 \mathrm{~nm})$ lasers in the treatment of facial and leg telangiectasias," Dermatol. Surg. 24, pp. 221-226, 1998.

25. R.M. Adrian and E.A. Tanghetti, " Long pulse 532-nm laser treatment of facial telangiectasia," Dermatol. Surg. 24, pp. 71-73, 1998. 
20 / Critical Reviews Vol. CR75

26. R. Dummer, M.P. Goldman, M.A. Weiss and R.A. Weiss, “ Treatment of adult port-wine stains using intense pulsed light therapy (PhotoDerm VL): brief initial clinical report," Dermatol. Surg. 23, pp. 594-601, 1997.

27. R. Raulin, C.A. Schroeter, R.A. Weiss, M. Keiner and S. Werner, "Treatment of port-wine stains with a noncoherent pulsed light source," Arch. Dermatol. 135, pp. 679-683, 1999.

28. R.A. Massey and B.A. Katz, "Successful treatment of spider leg veins with a high-energy, long-pulse, frequency-doubled neodymium: YAG laser (HELP-G)," Dermatol. Surg. 25, pp. 677-80, 1999.

29. D.B. Apfelberg, M.R. Maser and H. Lash, "Argon laser treatment of decorative tattoos," Br. J. Plast. Surg. 32, pp. 141-144, 1979.

30. P.L. Bailin, J.L. Ratz, and H.L. Levine, "Removal of tattoos by $\mathrm{CO}_{2}$ laser," J. Dermatol. Surg. Oncol. 6, pp. 997-1001, 1980.

31. D.B. Apflberg, M.R. Maser, H. Lash, D.N. White, and J.T. Flores, " Comparison of argon and carbon dioxide laser treatment of decorative tattoos: a preliminary report," Ann. Plast. Surg. 14, pp. 7-16, 1985.

32. K.M. Cesario-Kelly and J.S. Nelson, "Invited review: Q-switched laser treatment of tattoos," Lasers Med. Sci. 12, pp. 89-98, 1997.

33. C.R. Taylor, R.R. Anderson, R.W. Gange, N.A. Michaud and T.J. Flotte, "Light and electron microscopic analysis of tattoos treated by Q-switched ruby laser," $J$. Invest. Dermatol. 97, pp. 131-136, 1991.

34. R.R. Anderson, R.G. Geronemus, S.L. Kilmer, W. Farinelli and R.E. Fitzpatrick, "Cosmetic tattoo ink darkening: a complication of Q-switched and pulsed-laser treatment," Arch. Dermatol. 129, pp. 1010-1014, 1993.

35. T.S. Alster, "Q-switched alexandrite laser treatment $(755 \mathrm{~nm})$ of professional and amateur tattoos," J. Am. Acad. Dermatol. 33, pp. 69-73, 1995.

36. R. Ashinoff, V.J. Levine and N.A. Soter, "Allergic reactions to tattoo pigment after laser treatment," Dermatol. Surg. 34, pp. 542-545, 1995.

37. R.M. Herd, M.B. Alora, B. Smoller, K.A. Arndt and J.S. Dover, "A clinical and histologic prospective controlled comparative study of the picosecond titanium:sapphire $(795 \mathrm{~nm})$ laser versus the Q-switched alexandrite $(755 \mathrm{~nm})$ laser for removing tattoo pigment," J. Am. Acad. Dermatol. 40, pp. 603-606, 1999.

38. E.V. Ross, G.S. Naseef, C.P. Lin, M. Kelly, N. Michaud, T.J. Flotte, J. Raythen and R.R. Anderson, "Comparison of responses of tattoos to picosecond and nanosecond Q-switched neodymium:YAG lasers," Arch. Dermatol. 134, pp. 167-171, 1998.

39. M. Hodersdal, N. Bech-Thomsen, and H.C. Wulf, "Skin reflectance - guided laser selections for treatment of decorative tattoos," Arch. Dermatol. 132, pp. 403-407, 1996.

40. A. Gulshan, R.R. Anderson, K.G. Mandel, M. Ottesen and A.R. Oseroff, "Irradiation of pigmented melanoma cells with high intensity pulsed radiation generates acoustic waves and kills cells," Lasers. Surg Med. 10, pp. 52-59, 1990.

41. R.R. Anderson, R.J. Margolis, S. Watenabe, T. Flotte, G.J. Hruza and J.S. Dover, "Selective photothermolysis of cutaneous pigmentation by Q-switched Nd:YAG laser pulses at 1064, 532, and 355 nm," J. Inves. Derm. 93, pp. 28-32, 1989. 
Matching the Energy Source to the Clinical Need / 21

42. D.J. Goldberg, "Congenital and acquired pigmented lesions: To treat or not to treat with lasers?" in Syllabus for Controversies and Conversations in Cutaneous Laser Surgery 1999.

43. C.R. Taylor and R.R. Anderson, "Ineffective treatment of refractory melasma and postinflammatory hyperpigmentation by Q-switched ruby laser," J. Dermatol Surg. Oncol. 29, pp. 592-597, 1994.

44. N.J. Lowe, J.M. Wieder, N. Shorr, C. Boxrud, D. Saucer, and M. Chalet, "Infraorbital pigmented skin preliminary observations of laser therapy," Dermatol. Surg. 21, pp. 767-770, 1995.

45. A. Rosenbach, C.M. Williams, and T.S. Alster, "Comparison of the Q-switched alexandrite $(755 \mathrm{~nm})$ and Q-switched Nd:YAG $(1064 \mathrm{~nm})$ lasers in the treatment of benign melanocytic nevi," Dermatol. Surg. 23, pp. 239-245, 1997.

46. D.J. Goldberg and T. Stampien, "Q-switched ruby laser treatment of congenital nevi," Arch. Dermatol. 131, pp. 621-623, 1995.

47. J.M. Grevelink, R.L. van Leeuwen, R.R. Anderson, and R. Byers, "Clinical and histological responses of congenital melanocytic nevi after single treatment with Q-switched lasers, "Arch. Dermatol. 133, pp. 349-353, 1997.

48. H.A. Waldrof, A.N. Kauvar, and R.G. Geronemus, "Treatment of small and medium congenital nevi with the Q-switched ruby laser," Arch. Dermatol. 132, pp. 301-304, 1996.

49. S. Ueda and S. Imayama, "Normal-mode ruby laser for treating congenital nevi," Arch. Dermatol. 133, pp. 355-359, 1997.

50. J.S. Nelson and K.M. Kelly, "Q-switched ruby laser treatment of a congenital melanocytic nevi," Dermatol. Surg. 25, pp. 274-276, 1999.

51. T.S. Alster, "The evolution of laser-assisted hair removal," Cosmetic Dermatol. August, pp. 15-18, 1999.

52. R.J. Ort and R.R. Anderson, "Optical hair removal," Sem. Cut. Med. Surg. 18, pp. 149-158, 1999.

53. C.C. Dierickx, M.C. Grossman, W.A. Farinelli and R.R. Anderson, "Permanent hair removal by normal-mode ruby laser," Arch. Dermatol. 134, pp. 837-842, 1998.

54. "Diode claims permanent hair reduction," Cosmetic Dermatol. 12, p. 481999.

55. M.H. Gold, M.W. Bell, T.D. Foster and S. Street, "One-year follow-up using an intense pulsed light source for long-term hair removal," J. Cut. Laser Therapy 1 , pp. 167-171 1999 .

56. C.A. Nanni and T.S. Alster, "A practical review of laser-assisted hair removal using the Q-switched Nd:YAG, long-pulsed ruby and long-pulsed alexandrite lasers," Dermatol. Surg. 24, pp. 1399-1405, 1998.

57. E.V. Ross, Z. Ladin, M. Kriendel and C. Dierickx, 'Theoretical considerations in laser hair removal," Derm. Clinics 17, pp. 333-355, 1999.

58. N.L. Marchell and T.S. Alster, "Evaluation of temporary and permanent hair removal methods," J. Aesth. Dermatol. Cos. Surg. 1, pp. 3-12, 1999.

59. C.A. Nanni and T.S. Alster, "Laser-assisted hair removal: Side effects of Qswitched Nd:YAG, long-pulsed ruby, and alexandrite lasers," J. Am. Acad. Dermatol. 41, pp. 165-171, 1999. 
60. M. Grossman, J. Wimberly, P. Dwyer, T. Flotte, and R.R. Anderson, "PDT for hirsutism," Lasers Surg. Med. 7(suppl), p. 44, 1995.

61. R.L. Moy, B. Bucalo, M.H. Lee, J. Wieder, M.D. Chalet, A. Ostad, and W. D Dishell, "Skin resurfacing of facial rhytides and scars with the $90-\mu$ s short pulsed $\mathrm{CO}_{2}$ laser," Dermatol. Surg. 24, pp. 1390-1396, 1998.

62. D. Duke, K. Khatri, J.M. Grevelink and R.R. Anderson, "Comparative clinical trial of 2 carbon dioxide resurfacing lasers with varying pulse durations, " Arch. Dermatol. 134, pp. 1240-1246, 1998.

63. J.M. Stuzin, T.J. Baker, T.M. Baker, and A.M. Kligman, "Histologic effects of the high-energy pulsed $\mathrm{CO}_{2}$ laser on photoaged facial skin," Plast.Reconstr. Surg. 99, pp. 2036-2050, 1999.

64. D. Ratner, Y. Tse, N. Marchell, M.P. Goldman, R.E. Fitzpatrick and D.J. Fader, "Cutaneous laser resurfacing" J. Am. Acad. Dermatol. 41, pp. 365-389, 1999.

65. E.V. Ross, M.C. Grossman, D.Duke and J.M. Grevelink, "Long-term results after $\mathrm{CO}_{2}$ laser skin resurfacing: A comparison of scanned and pulsed systems, " $J$. Am. Acad. Dermatol. 37, pp. 709-718, 1997.

66. K.J. Smith, H.G. Skelton, J.S. Graham, C.G. Hurst and J.E. Hackley, "Increased smooth muscle actin, factor XIIIa, and vimentin-positive cells in the papillary dermis of carbon dioxide laser-debrided porcine skin," Dermatol. Surg. 23, pp. 891-895, 1997.

67. T.S. Alster, "On: Increased smooth muscle actin, factor XIIIa, and vinentinpositive cells in the papillary dermis of carbon dioxide laser-debrided porcine skin," Dermatol. Surg. 25, p. 155, 1998.

68. E.V. Ross, J.R. McKinlay and R.R. Anderson, "Why does carbon dioxide resurfacing work?" Arch. Dermatol. 135, pp. 444-454, 1999.

69. R.E. Fitzpatrick, S.R. Smith, and S. Sriprachya-anunt, "Depth of vaporization and the effect of pulse stacking with a high-energy, pulsed carbon dioxide laser," J. Am. Acad. Dermatol. 40, pp. 615-622, 1999.

70. E.S. Garner, L. Reinisch, G.P. Stricklin and D.L. Ellis, "In vitro changes in nonfacial human skin following $\mathrm{CO}_{2}$ laser resurfacing; a comparison study," Lasers Surg. Med. 19, pp. 378-387, 1996.

71. J.T. Walsh, T.J. Flotte and T.F. Deutsch, "Er:YAG laser ablation of tissue: effect of pulse duration and tissue type on thermal damage," Lasers Surg. Med. 9 pp. 314-326, 1989.

72. Y. Tse, W. Manuskiatti, S.P. Detwiler, R.E. Fitzpatrick and M.P. Goldman, "Tissue effects of the erbium:YAG laser with varying passes, energy, and pulse overlap," Lasers Surg. Med. 22 (suppl 10), p.70, 1998.

73. N.J. Lowe, G. Lask, M.E. Griffin, A. Maxwell, P Lowe, and F. Quilada, "Skin resurfacing with the Ultrapulse carbon dioxide laser," Dermatol. Surg. 1995, 21: pp. 1025-1029, 1998.

74. H.A. Waldorf, A.N. Kauvar, and R.G. Geronemus, "Skin resurfacing of fine to deep rhytides using a char-free carbon dioxide laser in 47 patients," Dermatol. Surg. 21, pp.940-946, 1995.

75. K.A. Khatri, E.V. Ross, J.M. Grevelink, C.M. Magro, and R.R. Anderson, "Comparison of Erbium:YAG and carbon dioxide lasers in resurfacing of facial rhytides," Arch. Dermatol. 135, pp. 391-397, 1999. 
76. R.E. Fitzpatrick, M.P. Goldman, N.M. Satur and W. D. Tope, "Pulsed carbon dioxide laser resurfacing of photoaged facial skin," Arch. Dermatol. 132, pp. 395-402, 1996.

77. L.J. Bernstein, A.N. Kauvar, M.C. Grossman, and R.G. Geronemus, " The shortand long-term side effects of carbon dioxide laser resurfacing," Dermatol. Surg. 23, pp. 519-525, 1997.

78. N.J. Lowe, G. Lask, M.E. Griffin, "Laser skin resurfacing: Pre- and posttreatment guidelines," Dermatol. Surg. 21, pp. 1017-1019, 1995.

79. S.S. Collawn, "Combination therapy: utilization of $\mathrm{CO} 2$ and Erbium:YAG lasers for skin resurfacing," Ann. Plast. Surg. 42, pp. 21-26, 1999.

80. K.M. Kelly, J.S. Nelson, G.P. Lask, R.G. Geronemus, and L.J. Bernstein, "Cryogen spray cooling in combination with nonablative laser treatment of facial rhytides," Arch. Dermatol. 135, pp. 691-694, 1999. 